Behavioural Sciences | Professor Katsuyuki Hidaka

\section{In the wake of catastrophe}

Japanese media after the Fukushima nuclear disaster

\begin{tabular}{|c|c|}
\hline $\begin{array}{l}\text { The Fukushima nuclear disaster } \\
\text { in } 2011 \text { saw a clamour among } \\
\text { the Japanese media calling } \\
\text { for the phase-out of nuclear } \\
\text { power plants. In his research, } \\
\text { Professor Katsuyuki Hidaka at } \\
\text { Ritsumeikan University looks } \\
\text { at the discussions around } \\
\text { denuclearisation since the } \\
\text { catastrophe, and how they } \\
\text { reveal tensions within Japan's } \\
\text { social narrative. }\end{array}$ & $\begin{array}{l}\text { n } 11 \text { March 2011, an earthquake } \\
\text { measuring } 9.0 \text { on the Richter } \\
\text { scale triggered a tsunami off } \\
\text { the east coast of Japan. It hit Fukushima } \\
\text { Daiichi Nuclear Power Plant, causing a } \\
\text { triple core meltdown and radiation leak } \\
\text { that saw over } 470,000 \text { people evacuated } \\
\text { from their homes. } \\
\text { It was one of the worst nuclear disasters in } \\
\text { history, including the Chernobyl disaster, } \\
\text { and became the catalyst for a clamour } \\
\text { among the nation's media to call for a } \\
\text { ban of nuclear power in Japan, a country } \\
\text { with over } 50 \text { nuclear power stations and a } \\
\text { frequency of earthquakes. Public opinion } \\
\text { has shifted, too, with the majority of }\end{array}$ \\
\hline
\end{tabular}

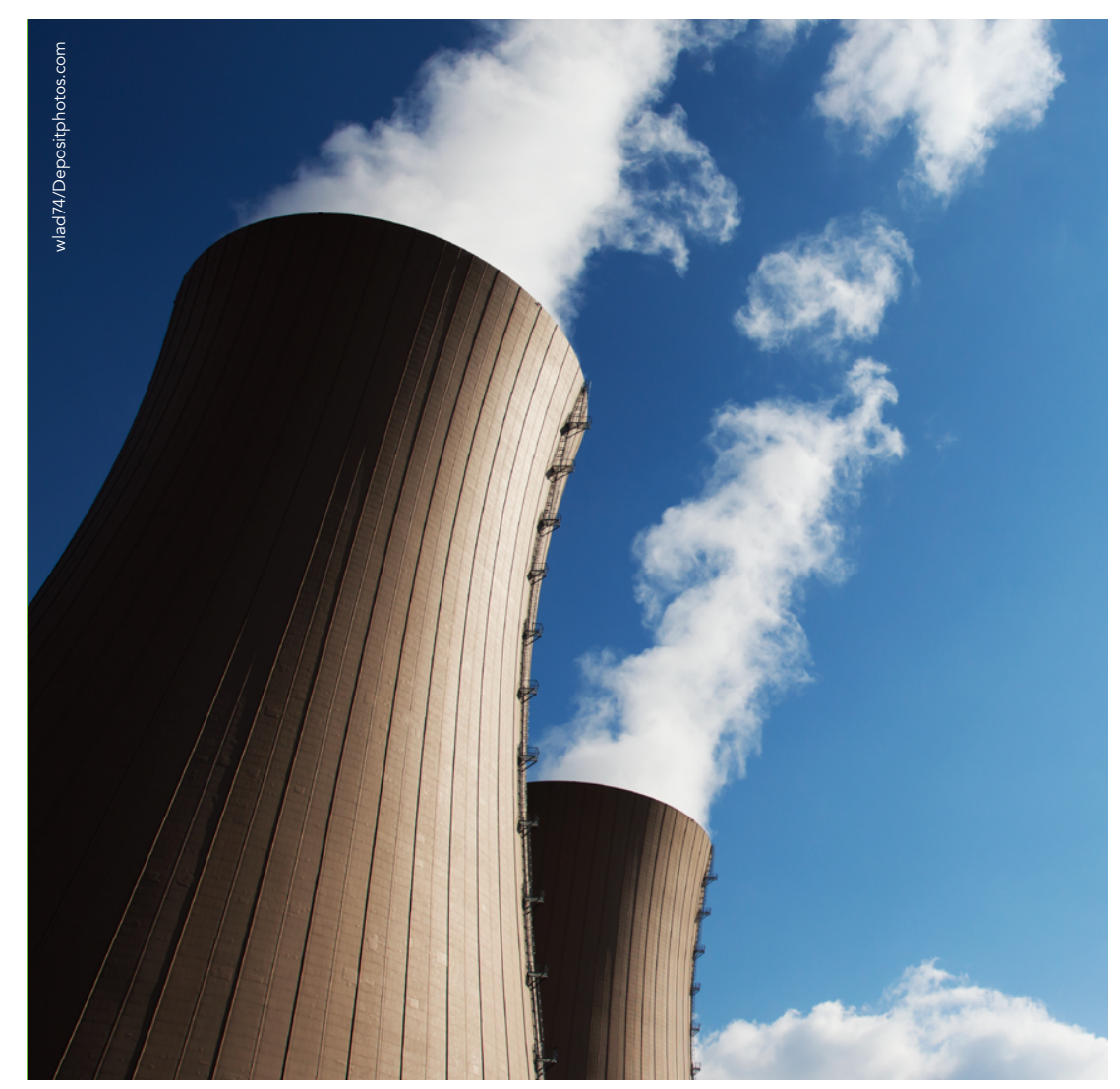

Japan's population keen to see the back ef nuclear power. Prior to the accident, antinuclear sentiments were confined to a minority of individuals, a taboo subject left minch

So how has the Fukushima incident shifted public, media and academic opinion in Japan, and how do these opposers put forward their arguments? interpretations of 'newcomers' to the antinuclear movement differ from those who've been fighting the cause for decades? This is something Professor Katsuyuki Hidaka is investigating in his ongoing research at Ritsumeikan University: he is exploring the media and academic discussions around nuclear power in the wake of the disaster, and crucially, how these discussions reflect an unease with Japanese modernity and postwar society. It is a topic that forms a larger part of Hidaka's research and makes sense of the past, particularly the recent past.

\section{THE RISE OF NUCLEAR POWER} In the two decades following the Second World War, nuclear power plants were constructed in quick succession around Japan, then slowed down dramatically in the 1970 s with the first rumblings of the antinuclear movement. The late 60s and 70 s were a hotbed of political with stunin other arenas in the country. etablisher fustrations at the wider This is something hill as at nuclear pow in his earlier studies, particularly looking heyday of politipan's nostalgia for its

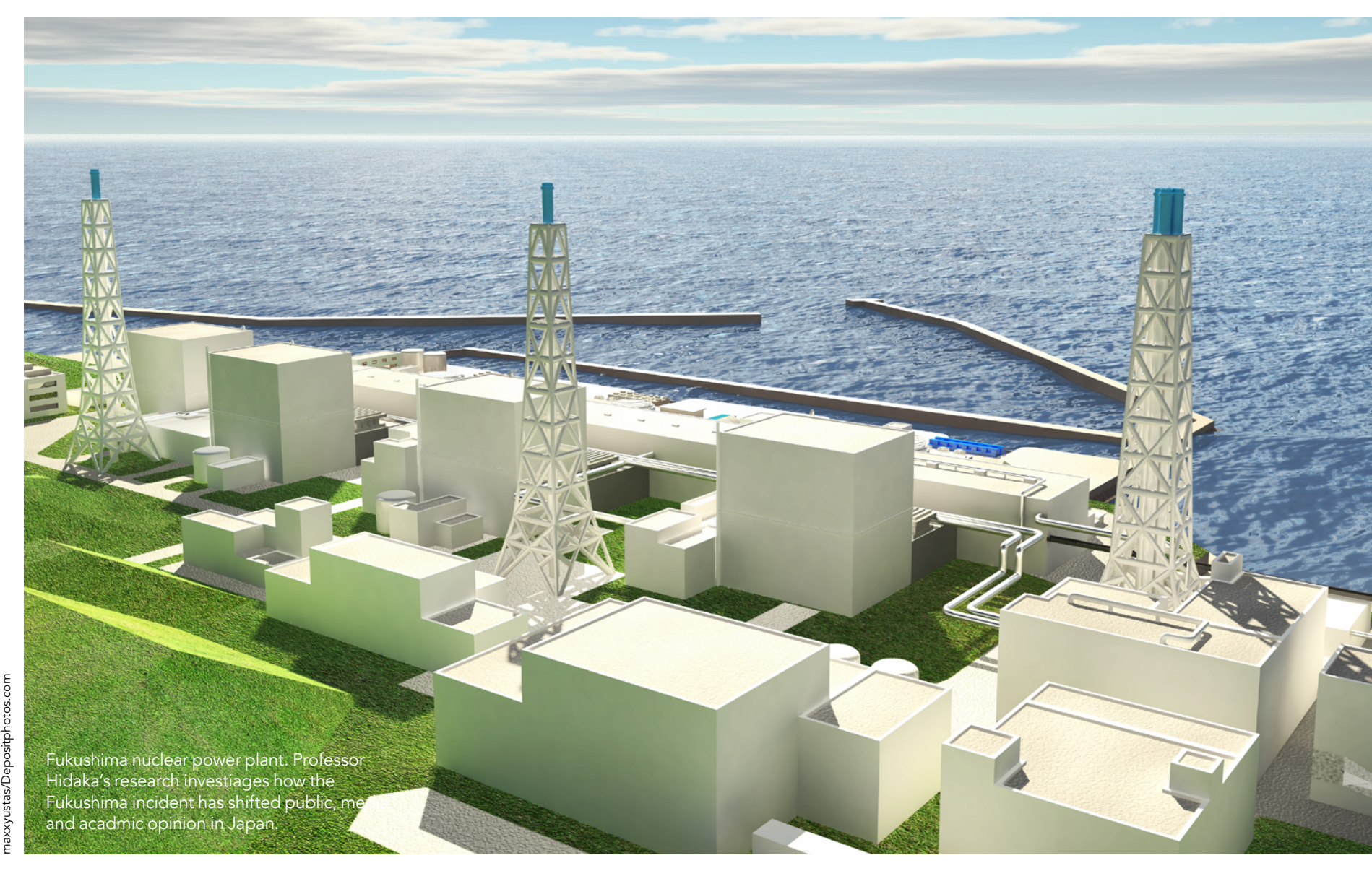

recent films about this rebellious period are a critique of the activists' assimilation into mainstream capitalist society and kowtowing to the powers that be.

The antinuclear movement gained further momentum after the nuclear accident on Three Mile Island in Pennsylvania in the United States in 1978, during the Cold War when figures from the Japanese their opposition to nuclear weapons and after the Chernobyl disaster in 1986. The latter disaster in particula prompted significant uproar prompting journalist Hirose Takashi to write Kiken na Hanashi ('Dangerous Stories'), arguing that information presented by the Soviet government about the incident was full of fabrications. The book particularly attracted housewives who were worried about radioactive contamination of foods imported from Soviet and European countries.

However, in the 1980s - a time of unprecedented economic growt
in Japan - the movement was in Japan - the movement was confined to the fringes of mainstream
Dr Hidaka explores the media and academic discussions around nuclear power in the wake of the disaster, and crucially, how these discussions reflect an

unease with Japanese modernity and postwar society.

photographers, pop musicians, literary scientists and those with alternative, left-wing leanings often labelled as 'hippies'. The 1990 s was a quiet spell of memory of the Chernobyl disaster, and perhaps also due to Japan's economic bubble bursting in 1992 the resulting economic stagnation in the country would have distracted the populace from other pressing issues. nuclear accidents involving reactor damage and ruptured pipes, which are believed to have been covered up by the by the media at the time.

According to Hidaka, the gravity worldwide attention it received seemed to be a wakeup call for Japa Mainstream news outlets suddenly jumped on the antinuclear bandwagon sciences and humanities, who were previously indifferent to the movement lent their voices to the cause, airing their discontent through a proliferation of newspaper and magazine articles, blog posts and books. Hidaka claims that this is in line with a recent trend of catastrophic disasters, such as wars, major earthquakes and terrorist attacks, being fodder for the mass media, which of these events. for the movement owing to the fading

Even the 2000s were a quiet time despite and academics from the world of social 


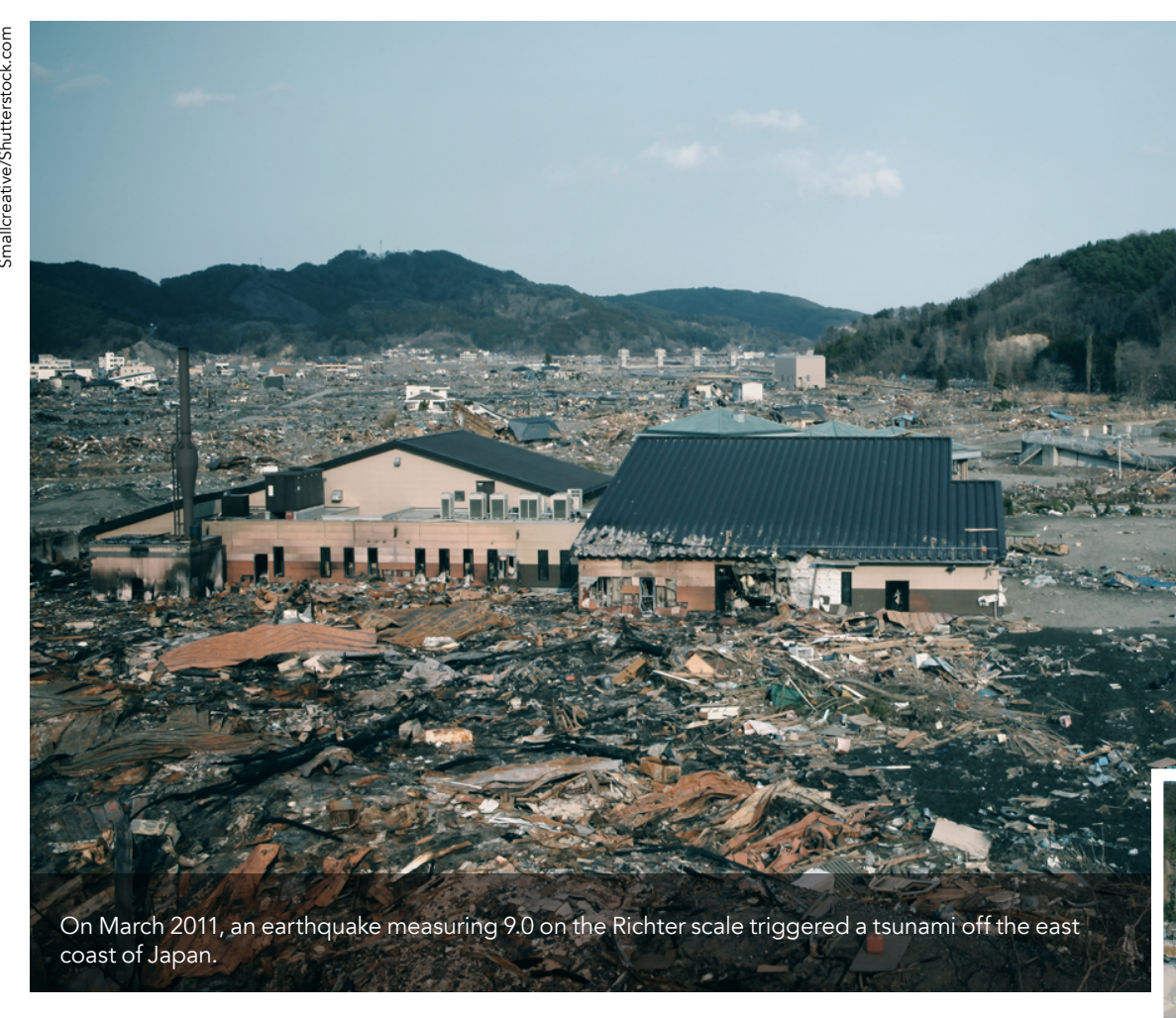

According to Hidaka, the gravity of the Fukushima disaster and the worldwide attention it received seemed to be a wakeup call for Japan.

In his research, Hidaka highlights that the antinuclear discussions around Fukushima fall into four categories: reasons for how and why the disaster happened; the impacts and influence of the disaster; the pros and cons of nuclear energy; and nuclear power stations in ap nut Hidata found that the first two fields of discussion are often presentedin newspaper and magazine articles, while the batter two largely addressed by experts from vanying backgrounds of expertise, including engineering, risk management and economics. He also noticed a trend for academic offerings to be inadvertently biased by the author's specialist field of knowledge, whether it be philosophy, religion, economics or otherwise, creat a nuanced macro-narrative that fals to paint a broader, holistic picture.

LIFTING THE LID ON 'COOL JAPAN' Hidaka also observed that these antinuclear discussions, which are still a hot topic in Japanese current affairs
today, reflect a deep-seated discontent with Japanese modernity and a post-war money-driven society. He highlights tha this is something rarely given attention to by the media, with most focus being on the notion of 'Cool Japan' and its gaming to the world stage rather th plitical probs dids sociothat it often takes a national catastroph like Fukushima to shine a light on these issues, quoting Kai Erikson: "A catastrophe opens up the cracks that were inherent in the previous commun and exposes cultural contradictions while fragmenting them."

Hidaka then takes this argument down an interesting avenue, highlighting that these post-Fukushima discussions have a lot in common with media and in Japanese history, such as the Great people in 1923, and the Pacific Air War in 1942. The former disaster put forwar contributions of manga, anime and intellectual discourse after other disasters Kanto Earthquake that killed 100,000

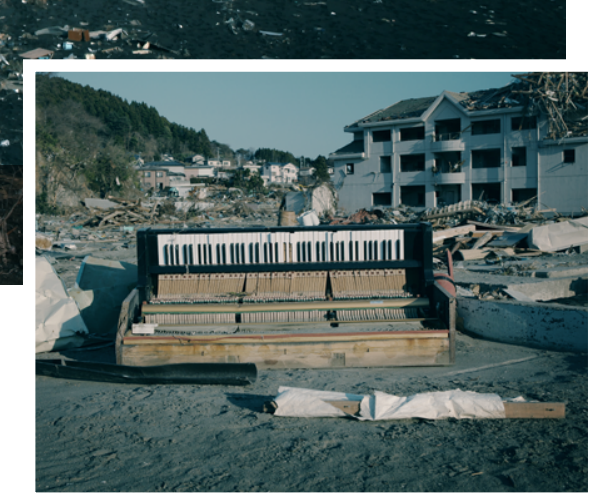

latter prompted concerns about Japan's path of modernisation.

But a key question Hidaka wishes to answer in his research is why - in a country where earthquakes are a frequen occurrence - a denuclearisation policy hasn't been infoduced until now, even though the vast majorty of Japanese there is no simple answer to this and is something he endearours to anplore in his ongoing study of the Japanese media's representation of the country's

To highlight the Japanese public's condemnation of modern society after the Fukushima disaster, in his study Hidaka quotes the Nobel Prize winning novelist Oe Kenzaburō: "So far, the Japanese as subjects have not had the determination nor have they been given the option to shape the nation's future. th is as if Japan has been giving herself a postponement... This actually mean that our nation has not corrected its past mistake yet. We have not taken our respons libily las maden citizens Professor Katsuyuki Hidaka

E: k-hidaka@wa2.so-net.ne.jp

W: https://www.soas.ac.uk//staff/stafff90359.php

Research Objectives

Professor Hidaka's research explores the manner through which media industries integrate collective interests and memories into media narratives.

\section{Detail}

Professor Katsuyuki Hidaka

sciences, Ritsumeikan University, 56-1, Toji-in Kitamachi,

Kita-ku,

Kyoto, 603-8577,

Japan

Bio

Dr Katsuyuki Hidaka is Professor of Media and Cultural Studies at Ritsumeikan University in Kyoto, Japan. He is also a research associate at the School of Oriental and African Studies, University of London, from which he received his of the Twenty-first Cenapanese Media at the Beginning 2017) wont the Jirst Century: Consuming the Past (Roultedge, Book Award. He is director of JSSJMC (the Japan Society Book Award. He is director of JSSJMC (the Japan Society

Funding

- Tresearch in Japan

\section{R Ritsumeikan}

\section{References}

Hidaka, K. "Collective Remorse for the Past: Japanese Film and TV Representations of the 1960s Student Movement." In: Persistently Postwar. Media and the Politics of Memory in Japan. Eds. Blai Guarné, Artur Lozano-Mendez, and Dolores P.

Hidaka, K. Japanese Media at the Beginning of the 21st Century: Consuming the Past (Routledge Contemporary Japan Series). Kassuyuki Hadaka. 2016. Wand or the Japan https://doi.org/10.4324/9781315537191

\section{Personal Response}

What does the next stage of your research entail?

II My aim is to collate my research to date and publish it as a single-authored book. I will then investigate the various including the Titanic accident, September 11 attacks, and atomic bombing of Hiroshima, and compare these with the media situation after the Fukushima nuclear accident.

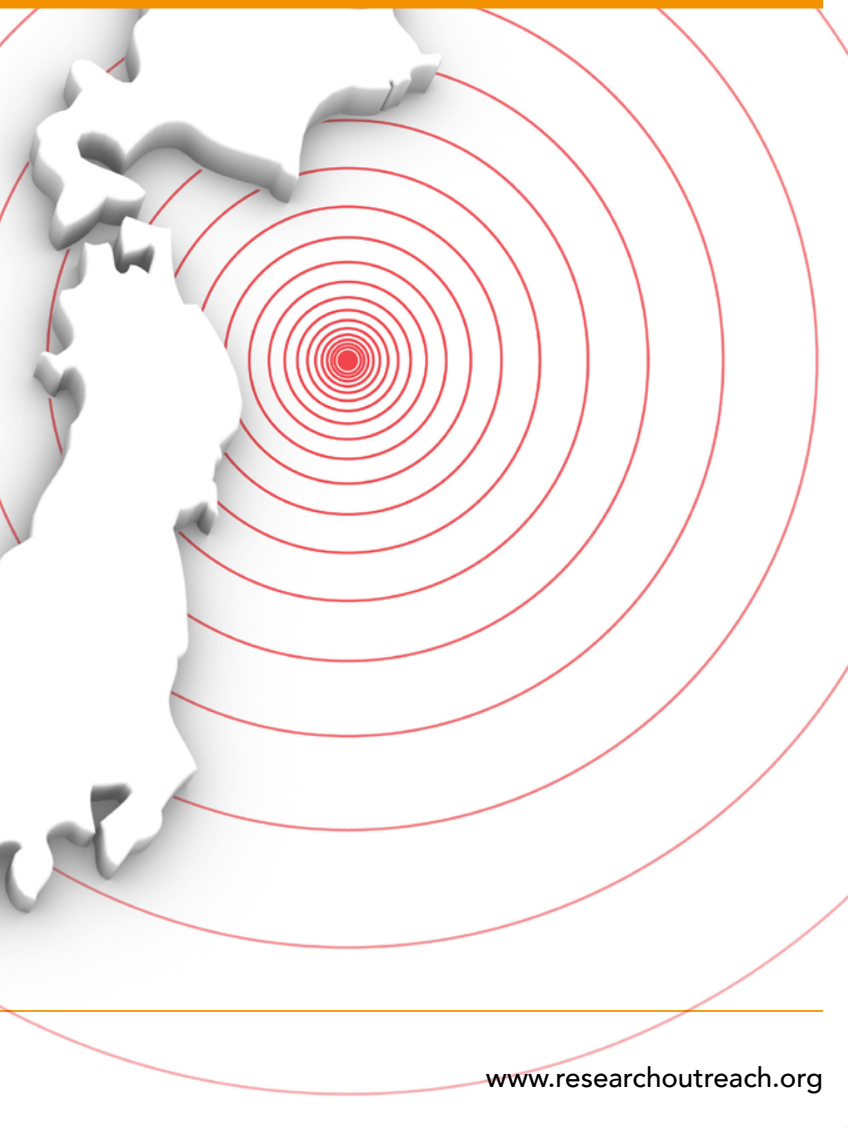

